$\begin{array}{cccc}\text { S sciendo } & \text { International Conference KNOWLEDGE-BASED ORGANIZATION } \\ \text { Vol. XXV } & \text { No } 1 & 2019\end{array}$

\title{
SOME CONSIDERATIONS RELATED TO NATO INTERVENTION FOR DISASTER MITIGATION (CASE STUDY: PAKISTAN EARTHQUAKE)
}

\author{
Ioan-Dan POPA \\ "Nicolae Bălcescu" Land Forces Academy, Sibiu, Romania \\ paragon1971@gmail.com
}

\begin{abstract}
In the last period of time, disasters have become a regular part of global life, no matter if we consider natural or manmade disasters. These events create emergencies when their effects impact on nations/organizations which are not able to cope with the consequences, especially because of the lack of inherent resources. Hence, NATO has assumed an important role in international disaster relief by becoming involved in the provision of relief following natural disasters, all these being in accordance with the founding principles of the Alliance. The purpose of this paper is to spotlight the importance of NATO's specific structures dealing with disaster relief (EADRCC Euro-Atlantic Disaster Response Coordination Centre, EADRU - Euro-Atlantic Disaster Response Unit etc.) and to present the main aspects and lessons learned from the intervention in Pakistan earthquake (2005).
\end{abstract}

Keywords: Civil Emergency Planning(CEP); Disaster Relief Operations(DRO); North Atlantic Treaty Organization (NATO); Pakistani Earthquake; NATO Response Force (NRF)

\section{Introduction}

In the last period of time, disasters have become increasingly destructive, occurring on a more frequent basis. Hence, NATO's policy on international disaster relief acknowledges that natural disasters are posing an increasing risk to the international communities anticipating that "the number of people at risk to natural and technological disasters will increase dramatically over the next two decades "[1].

Undoubtedly, from the very beginning of its activity, NATO Alliance has been actively present not only in activities related to security and defence but also in missions in the area of civil protection and humanitarian support which encompasses disaster relief operations, as well. As a matter of fact, the Civil Emergency Planning Committee (CEPC) was created when NATO first developed its Civil Emergency Planning programme in the 1950's and a few years later, in 1953, NATO conducted its first disaster assistance operation following a natural disaster, due to The North Sea floods in England and Netherlands [2].

For a coherent, efficient and effective intervention in Disaster Relief Operations (DRO), NATO has developed some structures able to coordinate the supply of relief and to intervene in these specific missions, named EADRCCEuro-Atlantic Disaster Response 
Coordination Centre and EADRU-EuroAtlantic Disaster Response Unit.

At the same time, when deemed it necessary and with NAC-North Atlantic Council approval, NATO can deploy on the affected area of disaster some military assets which belong to NATO military command and force structures. In case of Pakistani earthquake, NATO used both options, activation of EADRCC/EADRU and deploying on the spot of NRF-NATO Response Force, respectively.

\section{Main NATO structures dealing with Disaster Relief Operations (DRO)}

\subsection{Civil Emergency Planning (CEP)}

NATO Civil Emergency Planning (CEP) has become more important than ever, covering various dimensions of NA5CRO (Non Article 5 Crises Response Operations), its role being to collect, analyse and share information in order to use in the most effective way the resources of alliance designated to emergency situations. CEP acts as an enabler, having a network of experts who are specialized in the area of civilian resources.

Besides this network of civil experts, the Senior Civil Emergency Planning Committee (SCEPC) serves as the top NATO advisory body for disaster relief operations, as its role is to ensure that support for national authorities is executed in accordance with the Alliance's objectives. An important characteristic of CEP is that civil assets remain a domestic affair, being permanently under control and responsibility of the national authorities. When a disaster has occurred in one country which is overwhelmed and cannot provide the necessary disaster assistance, NATO gets involved, its primary role being to help the affected nation to better handle the protection of civilian populations. At the same time, CEPC oversees the activities of the Euro-
Atlantic Disaster Response Coordination Centre (EADRCC).

\subsection{The Euro-Atlantic Disaster Response Coordination Centre (EADRCC)}

This special structure was established at NATO Headquarters, within the Alliance's Civil Emergency Planning Directorate (CEPD), on 29 May 1998, serving as NATO's primary practical civil emergency response mechanism and being responsible for the coordination of international relief efforts of all 50 EAPC-Euro-Atlantic Partnership Council states (29 NATO and 21 Partner countries). The creation of EADRCC was initiated following a proposal from Russia to enhance the Euro-*Atlantic response capability, resulting in the "EAPC Policy on Enhanced Practical Cooperation in the field of International Disaster Relief'.

EADRCC activity is highly appreciated due to the promotion of information sharing, through organizing seminars and conferences, and also through facilitating close and continuing cooperation for training and exercises among voluntary groupings of EAPC member countries. Field exercises are organized each year and serve the objective of increasing interoperability and enhancing cooperation among nations, by applying EADRCC SOPs.

The EADRCC is responsible for the deployment of the Euro-Atlantic Disaster Response Unit (EADRU), which is activated whenever one or more EAPC member countries deploy capabilities in response to any disaster [3].

\subsection{The Euro-Atlantic Disaster Response Unit (EADRU)}

In accordance with the EAPC basic document, EADRU is the main tool of EADRCC, composed from multi-national mix of national civil and military elements, which are offered by EAPC countries on a volunteer basis. The composition and the size of this multinational unit will be determined after the assessment of each 
particular disaster. Extremely important is the fact that national elements remain under their respective national control while deployed in the affected country as an asset of the Local Emergency Management Authority (LEMA) [4].

\subsection{The Rapid Reaction Team (RRT) and the Advisory Support Team (AST)}

The Rapid Reaction Team and the Advisory Support Team represent another non military tools for CEP. RRT was established in 2006 by the SCEPC and has the capability to deploy a team of specialists in order to evaluate the necessary assets to cope with disaster and act in close cooperation with UNOCHA. The AST is mainly focused on the phase prior to a potential disaster, having the goal to improve the preparedness, response and recovery capabilities of nations. An AST is solely deployed when a nation directly requests assistance through the SCEPC and it is not mandatory for the nation to follow the recommendations of AST.

\subsection{Forces from NFS (NATO Force Structure)}

The activities conducted by NATO that do not fall under the Article 5 umbrella are considered as "Non". Article 5" and grouped under the concept of crisis response operations [4].

Sometimes NATO could decide that forces belonging to NFS have to be involved in DRO. NFS is composed of allied national and multinational forces and HQs, temporary or permanent, which are ready to intervene based on specific readiness criteria.

\section{Case study: NATO'S involvement in Pakistan earthquake (2005)}

Being the first intervention of NATO Forces in these kinds of missions, I consider this case study relevant to get some conclusions and lessons learned and to identify the appropriateness of involvement of NATO in Disaster Relief Operations.

\subsection{General aspects of the earthquake}

On 8 October 2005, a powerful earthquake (7.6 degree on Richter scale) affected the Northern part of Pakistan, causing a particularly high level of destruction to the Kashmir Region (Figure 1). It took place shortly after 8:50 a.m. local time and the epicenter was situated about 12 miles northeast of Muzaffarabad, the capital of Pakistan-administered Kashmir.

Because of the earthquake, were overall affected 3.2-3.5 million persons; 73,000 persons (including over 18,000 children) died; 70,000 persons were injured; 2.8 million remained without any shelter; 2.3 million persons without adequate food; 325,000 persons lost their jobs. Moreover, 400153 shelter units were destroyed or seriously damaged; 4844 educational facilities were destroyed (2647 damaged); 455 health facilities were destroyed (119 damaged); $4429 \mathrm{~km}$ of roads were damaged.

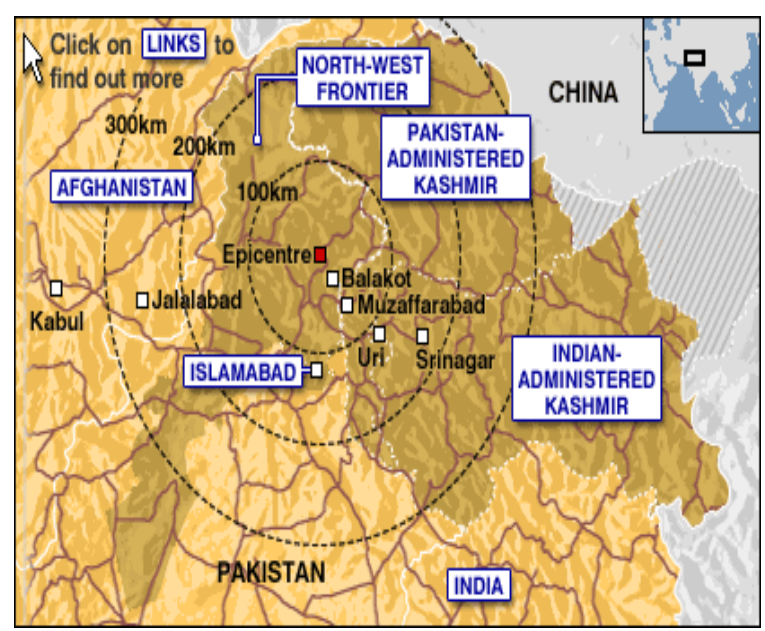

Figure 1: Pakistan earthquake map [5]

First relief efforts were conducted by the Pakistani military who provided an immediate response by coordinating the relief efforts and deploying around 60.000 troops in the affected area. Notwithstanding these first efforts, the Pakistani authorities and humanitarian organizations were incapable of dealing 
with the huge number of victims found on the spot. Moreover, the peculiarities of terrain, the extreme weather and low infrastructure downsized their attempts to provide relief efforts. In addition, winter was coming and the worsening weather conditions were another cause for concern. Taking all this into account, Pakistani government decided to request help from international organizations, including NATO.

\subsection{NATO'S involvement}

NATO intervention mainly consisted of 2 main phases, the first one being conducted by EADRCC (Air Bridge to Pakistan) and the second one was materialized by sending some troops belonging to NRF (NATO Response Force) on the spot. Due to the geopolitical aspects which existed in the region at that time, NATO assumed from the very beginning a 3 months period for this disaster relief operations mission. The timeline of the intervention is presented in Table 1.

\begin{tabular}{|c|c|}
\hline Timeline & Activities \\
\hline 8 October & Earthquake hit Pakistan \\
\hline 10 October & $\begin{array}{l}\text { Request for assistance by } \\
\text { Pakistani authorities }\end{array}$ \\
\hline 11 October & NAC approves airlift \\
\hline 21 October & $\begin{array}{l}\text { Approval deployment ground } \\
\text { forces }\end{array}$ \\
\hline 24 October & $\begin{array}{l}\text { Deployment DJTF HQ } \\
\text { Deployment air component }\end{array}$ \\
\hline 29 October & Deployment land component \\
\hline 6 November & First NATO helicopters \\
\hline 9 November & $\begin{array}{l}\text { NATO Hospital (NMH) starts } \\
\text { activities }\end{array}$ \\
\hline $\begin{array}{l}10 \\
\text { November }\end{array}$ & Start engineering support \\
\hline 1 February & End of the mission \\
\hline
\end{tabular}

Table 1. Timeline for NATO intervention in Pakistan earthquake 2005

\section{Stage 1: NATO'S air bridges}

One day after the request from Pakistani authorities was received, the NAC decided that NATO's role would be to coordinate, through EADRCC, the transportation of the aid supplies that were offered by EAPC countries, as follows:

$\checkmark$ transportation assistance for United Nations;

$\checkmark$ NATO Air-bridge used by 19 EAPC, 2 non-EAPC nations, WFP, UNJLC and UN-HCR;

$\checkmark$ more than 160 flights with almost 3,500 tons of relief goods $(18,000$ tents; 510,000 blankets; 17,000 heaters; 30,000 mattresses; 55,000 sleeping bags; many tons of medical supplies).

\section{Stage 2: Deployment of military assets on the ground}

Following an additional request from the Pakistani authorities, NATO initiated the second stage of the disaster relief operation, in which specialized units from the NRF were deployed on the ground. In fact, for this mission was nominated the NATO Rapid Deployable Corps from Madrid, Spain (NRCDC-SP), under de coordination of Joint Command Lisbon (JCL). More importantly, this disaster relief operation led by the Alliance was NATO's first major relief operation outside the Euro--Atlantic territory and the NRF's first major deployment. The main functions delivered by NRDC-SP in this operation were focused on engineers, medical support and CIMIC missions. The forces were tailored to the mission so the engineers had to be reorganized from a typical war fighting engineer unit into an ad-hoc unit able to perform disaster relief operations and the synchronization with other entities from the theatre was of paramount importance.

The engineers tremendous effort during the mission could be understand from the following facts:

$\checkmark 100.000$ manpower hours;

$\checkmark 16.000$ heavy machinery hours; 
9 semi-permanent buildings;

$\checkmark 60$ shelters, 17 health centers, 43 schools;

$\checkmark 26$ shelters, 23 schools \& 3 health centers winterized;

$\checkmark 41.000 \mathrm{~m} 3$ debris removed $(4.100$ trucks);

$\checkmark 18$ retaining walls built;

$\checkmark 20.000$ linear meters of road cleared of landslides;

$\checkmark 15.000$ linear meters of road cleared of snow;

$\checkmark$ drainage in Bagh main streets cleaned (1.000 meters);

$\checkmark 270.000$ liters of drinking water distributed in BAGH and ARJA.

More than 130 projects and tasks related with CIMIC missions were performed by forces deployed on the ground, contributing in this way, to the improvement of general situation in the area.

The medical statistics are proving the hard work of the medical staff and their achievements, as follows:

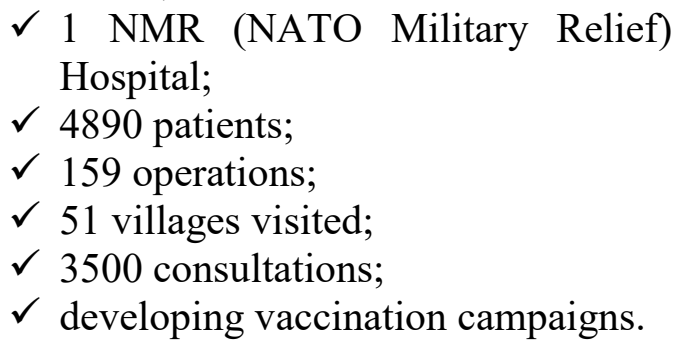

\section{Conclusion}

NATO's important contributions, as mentioned above, became clear during the Pakistan earthquake response and this case study showed that some time was lost in the deployment of forces and there is a need for improving NATO decision-making process, to foster cooperation and dialogue between civilian and military actors, at all levels and to increase cooperation with the potential host nations. Some general conclusions and lessons learned from this important mission are listed below:

a) Related to planning process:

$\checkmark$ coordination needs to begin as soon as possible in the planning stage; the use of liaison officers as early as possible is also essential to effective civil military cooperation;

$\checkmark$ the status of forces and memorandum of understanding concerning host nation and forces contributing nations is also something that must begin as early as possible;

$\checkmark$ during the initial planning phases for an operation of this type it is also important to have plans for transition and force withdrawal.

b) Related to execution process:

$\checkmark$ a key challenge was the lack of common understanding among all stakeholders regarding the priority of humanitarian needs;

$\checkmark$ lack of familiarity and understanding of the role of NATO among Pakistani opinion formers such as politicians and media;

$\checkmark$ a sizeable portion of the population did not speak english so interpreters and translators were essential;

$\checkmark$ the adaptability and effective decision making process of the Pakistani authorities was widely appreciated by the huge array of actors involved in the operation;

$\checkmark$ NATO's important role would not have been possible without the efforts of the Pakistani Army.

c) Related to logistics and engineering:

$\checkmark$ the existing logistic and transportation resources were limited. Every possible form of transport was used from porters to mules to aircraft;

$\checkmark$ the engineer package needs to be carefully tailored and balanced to the specific mission: lightly equipped engineers are an easier beast to move into, but heavy engineering assets make quicker progress;

$\checkmark$ services and supplies should be procured as close to the area of need as posible; this reduces the logistic 
bill and ensures that the supplies are compatible to the local culture;

$\checkmark$ financial resources not only facilitate the deployment of the force but helps get tasks done.

To sum up, this case study reaffirmed once again that NATO and its structures should be considered a crucial actor with meaningful contributions in Disaster Relief Operations. Its added value is obviously through highly integrated structure, specific capabilities that it can offer in times of disasters and its ability to establish good cooperation with all involved actors.

\section{References}

[1] *** EAPC policy on Enhanced practical cooperation in the field of international disaster relief, NATO Publishing House, para. 2.

[2] *** International CEP Handbook, Civil Emergency Planning in the NATO/EAPC Countries, Published by the Swedish Civil Contingencies Agency (MSB), 2006.

[3] https://www.nato.int/cps/en/natohq/topics_117757.htm

[4] AJP 3.4-Allied joint doctrine for non-article 5 Crisis Response Operations, NATO Publishing House, 2010, p. xi.

[5] http://news.bbc.co.uk/2/hi/south_asia/4322624.stm 